\title{
Performance, ventilation, and oxygen consumption in three different types of exercise test in patients with chronic obstructive lung disease
}

\author{
CR SWINBURN, JM WAKEFIELD, PW JONES \\ From the Department of Medicine, Middlesex Hospital Medical School, London
}

ABSTRACT Seventeen patients (six men and 11 women, mean age 66 years) with severe chronic obstructive lung disease (mean $\mathrm{FEV}_{1} 0.8$ (SD 0.3)l) performed three different types of exercise test on four occasions within one week. Three daily doses of placebo tablets were given between the third and fourth attempt at each test. The tests were the 12 minute walking test, a fixed rate and height paced step test, and a cycle ergometer test in which the work rate was increased by 10 watts each minute. Performance increased significantly $(\mathrm{p}<0.01)$ between the first and fourth attempts in each type of test (12 min walking distance 16\% (SD 20\%); steps climbed $96 \%$ $(74 \%)$; duration of cycling $29 \%(41 \%))$. There was a trend for the increase in performance between successive attempts to become progressively smaller but this was not significant. No effect of placebo on exercise performance was detected. The greatest intersubject range of performance was seen in the step test (14-126 steps) and the least in the walking test (438$1014 \mathrm{~m})$. Significant correlations $(\mathrm{p}<0.01)$ were observed between performance in all three types of exercise test, but the correlations found between the results of the various tests of exercise performance and the $\mathrm{FEV}_{1}$ and the $\mathrm{FVC}$ were either weak $(\mathrm{p}<0.05)$ or non-significant. Ventilation $(\dot{\mathrm{VE}})$ and oxygen consumption $\left(\dot{\mathrm{Vo}}_{2}\right)$ were subsequently measured and compared in eight patients during all three types of exercise test. Both the $\dot{V} E$ and the $\dot{V}_{2}$ that were achieved in the step test were significantly greater than in either the cycle or the walking test. No patient was able to reach and sustain steady state values of $\dot{V} E$ and $\dot{V}_{2}$ in the step test, whereas a steady state for both $\dot{V}_{E}$ and $\dot{V}_{2}$ was reached and sustained by all eight patients in the walking test. It is suggested that at least three practice attempts at any exercise test should be made before the introduction of either placebo or specific pharmacological treatment and that even then it may be necessary to allow for the effects of further repeated testing in the assessment of the results of treatment.

A large component of the morbidity of chronic obstructive lung disease results from exertional breathlessness and restriction of physical activity. The 12 minute walking test ${ }^{1}$ was introduced in an attempt to quantify the effects of disease on exercise capacity and has subsequently become widely used. It has become apparent that there is, at best, only a weak ${ }^{1}$ and sometimes no $^{2}$ relationship between the severity of airflow obstruction (assessed by the $\mathrm{FEV}_{1}$ and the forced vital capacity-FVC) and the performance of

Address for correspondence: Dr CR Swinburn, Department of Medicine, Middlesex Hospital, London W1N 8AA. (Reprints will not be available.)

Accepted 1 March 1985 patients in the walking test, so that disability cannot be accurately predicted from these simple measurements of pulmonary function. The walking test is a self paced measurement of exercise capacity and so may be influenced by factors other than pulmonary function, especially the attitudes and motivation of the patient, and these subjective factors have been shown to outweigh the FEV, and the FVC as predictors and determinants of performance in walking tests. ${ }^{34}$ In addition, walking is a familiar form of exercise and the observation that the distance walked in 12 minutes (12 MWD) can be accurately predicted from the distance walked in two or six minutes $^{5}$ suggests that patients select from experience and habit a speed which they know they are 
able to sustain without undue discomfort. This suggestion is supported by the observation that encouragement given to patients during the walking test significantly and substantially improves their performance in this test. ${ }^{6}$

The 12 MWD has been shown to improve during the first three measurements in the short term ${ }^{2}$ and may in the longer term require many more attempts before a peak distance is reached.' Both "learning" and specific training are probably involved in this improvement, which may in addition depend on the pattern and frequency of testing. The $12 \mathrm{MWD}$ has been shown in two studies to show spontaneous variation of $8.2 \%$ (range $1-21 \%$ ) $^{2}$ and $9.2 \%$ (range $0-31 \%)^{8}$ in patients with clinically stable obstructive airways disease assessed at two weekly intervals, and this variability should be taken into account if the walking test is used to examine the effects of treatment on exercise capacity.

In the present study we have compared the characteristics of three different types of exercise test applied to a group of patients with severe chronic obstructive lung disease. The tests used were (1) the self paced 12 minute walking test, (2) a fixed rate paced step test, and (3) an increasing work rate test on a cycle ergometer.

\section{Methods}

Seventeen patients (six men and 11 women) with symptomatic chronic obstructive lung disease were studied. Twelve were ex-smokers and four were current smokers. Their mean age was 66 years (range 49-73). All were in a stable clinical condition and were receiving inhaled bronchodilator treatment, which was continued unchanged during the period of study. Their mean $\mathrm{FEV}_{1}$ after bronchodilator was 0.77 (SD 0.30) $l$ and their mean FVC 1.59 (0.56) 1.

\section{WALKING TEST}

The 12 minute walking test was performed as described by McGavin et al, ${ }^{1}$ in an enclosed hospital corridor $37 \mathrm{~m}$ long. The patients were instructed to cover as much ground as possible within the time allotted. Stops were permitted but no extra time was allowed. The tests were supervised by the same doctor on each occasion, who provided simple verbal encouragement every time the patient passed the control point.

\section{PACED STEP TEST}

The paced step test was performed with a $25 \mathrm{~cm}$ platform and a timer which sounded every four seconds. Patients were instructed to mount the platform with both feet immediately on hearing the timer and having mounted to dismount and await the next signal. Arm rails were provided, which the patients were encouraged to use. They were urged to continue for as long as they felt able.

This test was also performed by age and sex matched normal controls with no symptomatic evidence of lung disease. In this control group there were five men and five women per decade over the range $45-75$ years.

\section{CYCLE ERGOMETER TEST}

The tests were performed on an electrically braked cycle ergometer (Lanooy). Heart rate was recorded with an electrocardiogram. A noseclip was worn and expired gas was collected via a mouthpiece and 115 ml dead space two way valve (Hans Rudolf Type 2700 ). Ventilation ( $\left.\dot{V}_{E}\right)$ and oxygen consumption $\left(\dot{\mathrm{Vo}}_{2}\right)$ were measured every 20 seconds with commercially available computerised equipment incorporating a rolling seal spirometer and dynamic mixing of the expired gas (Gould 9000 IV). Exercise was preceded by a four minute rest period. The ergometer was set running at $50-60 \mathrm{rev} / \mathrm{min}$ by an investigator, so that the patients did not have to overcome the inertia of the machine. The work rate was increased by 10 watts every minute and started at a setting of 10 watts. The patients were instructed to maintain a pedal frequency of $50-60 \mathrm{rev} / \mathrm{min}$ and to continue pedalling until they indicated their desire to stop.

\section{PROTOCOL}

The patients were admitted to hospital. No change was made to their usual treatment. Spirometric values were recorded daily at 9.00 am one hour after inhalation of salbutamol $(200 \mu \mathrm{g})$. The highest value from three attempts was recorded. On days when exercise performance was tested all three forms of exercise assessment were conducted. At least one hour was allowed to elapse between tests, which were performed at similar times of day in the same sequence. Exercise tests were performed on the first three consecutive days during the admission with no change in treatment and were repeated after three daily doses of placebo tablets.

\section{VENTILATION AND OXYGEN CONSUMPTION}

DURING THE WALKING AND STEP TESTS

Eight patients performed two additional walking and step tests, in which performance was deliberately matched by the observer to their previous best attempts. Ventilation and oxygen consumption were measured with a face mask and a portable device (Oxylog, PK Morgan). This instrument measures ventilation from the inspiratory airflow and calculates oxygen consumption from this and the averaged mixed expired oxygen concentration, on the 
basis of a gas exchange ratio of 1.0. During the step test the device was placed next to the subject and during the walking test it was carried by the observer. The performance of the Oxylog was standardised against the computerised equipment used for the cycle test by recording $\dot{V}_{2}$ and $\dot{V} E$ simultaneously on the two sets of equipment. For this comparison the equipment was connected in series, the expired gas passing first through the Oxylog and then to the other equipment. There were no significant differences in $\dot{V} E$ or $\dot{V}_{2}$, measured over the range of work rates that these patients could achieve. The mean differences relative to the computerised equipment were: $\dot{V}_{E}-0.06$ (SEM 0.2) and $\dot{V}_{2} 0.02$ (SEM 0.01) $1 \mathrm{~min}^{-1}$. Data from only the second of these additional experiments are quoted in the results.

\section{Results}

Results are expressed as means with standard deviations in parentheses.

\section{PERFORMANCE IN THE THREE TYPES OF}

EXERCISE TEST

The results achieved in the third and fourth attempts at each test were averaged and are summarised in table 1 . The patients displayed a wide range of exercise capacity. The greatest between patient variation in performance was seen in the step test and the least in the walking test. The average maximum work rate achieved on the cycle ergometer was 40 watts.

\section{PACED STEP TEST IN NORMAL SUBJECTS}

All the subjects were able to complete 150 steps before being asked to stop after 10 minutes of stepping. In this group steady state values, defined as being within $5 \%$ of the maximum value recorded in any one minute of the test, were reached in all subjects within five minutes of starting exercise in the case of oxygen consumption and within six minutes in the case of minute ventilation.
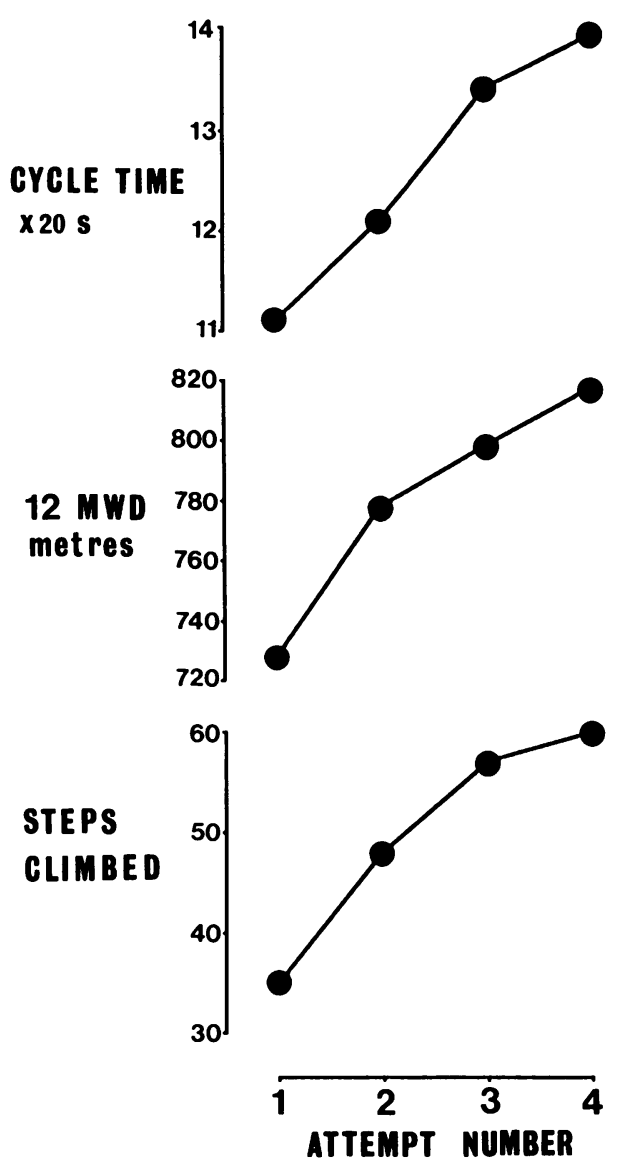

Fig 1 Mean performance of the group in the three types of exercise test over the four attempts. Placebo was given between the third and fourth attempt.

\section{OXYGEN CONSUMPTION AND VENTILATION IN}

THE THREE TYPES OF EXERCISE TEST

In eight of the patients (mean weight $76.3(10.7) \mathrm{kg}$, mean height $1.71(0.07) \mathrm{m})$ minute ventilation $\left(\dot{\mathrm{V}}_{\mathrm{E}}\right)$ and oxygen consumption ( $\mathrm{Vo}_{2}$ ) were measured during all three types of exercise performed within a 24

Table 1 Performance, minute ventilation $\left(\dot{V}_{E}\right)$, and oxygen consumption $\left(\dot{V}_{O_{2}}\right)$ in the three types of exercise test

\begin{tabular}{|c|c|c|c|c|}
\hline & \multirow[t]{2}{*}{$n$} & \multicolumn{3}{|l|}{ Test } \\
\hline & & Cycle (seconds) & Steps (No of steps) & Walk (m) \\
\hline $\begin{array}{l}\text { Performance, mean (SD) } \\
\text { (range) } \\
\bigcup_{\mathrm{E}}(\mathrm{I} \text { min } \\
\mathrm{VO}_{2}\left(\mathrm{ml} \mathrm{min}^{-1}\right)^{*}, \text { mean }(\mathrm{SD}) \\
\end{array}$ & $\begin{array}{r}17 \\
8 \\
8\end{array}$ & $\begin{array}{c}260(95) \\
(100-460) \\
26.9(7.4) \\
807(199)\end{array}$ & $\begin{array}{c}59(32) \\
(14-126) \\
31.3(5.3) \ddagger \\
1010(190) \dagger^{\prime} \\
\end{array}$ & $\begin{array}{c}807(155) \\
(438-1014) \\
27.4(5.1) \\
854(140)\end{array}$ \\
\hline
\end{tabular}

*The values are the maximum values recorded during any complete minute of exercise. For the cycle and step tests this was invariably the final complete minute of exercise.

$\dagger p<0.05, \ddagger p<0.01$ in comparisons with the results from other types of test (two way analysis of variance). 
hour period. The performance in the step and walking tests was the same with and without the Oxylog (12 MWD without Oxylog 918 (135) m, with Oxylog 917 (139) m; steps climbed without Oxylog 89.6 (24.6), with Oxylog 89.6 (22.2)). Steady state values, as defined above for normal subjects, for both $\dot{V}_{E}$ and $\dot{V}_{2}$, were reached within six minutes in all eight subjects during the walking test and were then sustained for the remainder of the test. No patient reached a steady state for either $\dot{V}_{E}$ or $\dot{V}_{O_{2}}$ during the step test. The maximum levels of $\dot{V}_{\mathrm{E}}$ and $\dot{V o}_{2}$ achieved in each type of test are summarised in table 1. The maximum values for $\dot{V}_{E}$ and $\dot{V}_{2}$ achieved in the step test were significantly greater than the corresponding values from the cycle and walking tests. Peak VE during walking was on average $12 \%$ and $\dot{\mathrm{Vo}}_{2} 15 \%$ lower than the corresponding peak levels achieved during the step test. The peak levels recorded during the last 20 seconds of the cycle test (that is, the last period of the highest work rate) were 29.6 (7.4) $1 \mathrm{~min}^{-1}$ for $\dot{V}_{E}$ and 892 (199) $\mathrm{ml} \mathrm{min}^{-1}$ for $\mathrm{Vo}_{2}$. These values were still less than the levels achieved during the last complete minute of stepping.

\section{CHANGES IN EXERCISE PERFORMANCE AND} SPIROMETRY ON REPEATED TESTING

The FEV and FVC both showed a $9 \%$ increase between the first and second daily measurements that did not reach significance. Thereafter the mean change between tests was small-less than $\pm 2 \%$.

There was a progressive and significant increase in performance in all three types of exercise test between the first and fourth measurements (analysis of variance $p<0.01)$. The overall increases in performance were: steps climbed $96 \%(74 \%)$, duration of cycle exercise $29 \%(41 \%)$, and 12 MWD $16 \%$ $(20 \%)$ (fig 1). In each case there was a significant linear regression between attempt number and performance. When a quadratic regression was fitted to the data the second order component was negative for each type of exercise, indicating a tendency for the increase in performance between successive attempts to become progressively smaller; but this curve did not fit the data significantly better than did

Table 2 Correlations $\left(r^{2}\right)$ between spirometric values and exercise performance on funal exercise day

\begin{tabular}{lllll}
\hline & FVC & Cycle & Walk & Steps \\
\hline FEV & $0.56 \dagger$ & 0.15 & 0.13 & $0.25^{*}$ \\
$\begin{array}{l}\text { Forced vital capacity } \\
\text { (FVC) }\end{array}$ & - & $0.30^{*}$ & 0.17 & $0.28^{*}$ \\
Cycle & - & - & $0.51 \dagger$ & $0.74 \ddagger$ \\
Walk & - & - & - & $0.52 \dagger$ \\
\hline${ }^{*} p<0.05, \dagger p<0.01, \ddagger \mathrm{p}<0.001$. & & &
\end{tabular}

the linear regression. The increase in performance seen between the third and fourth attempt at each test, while placebo was being given, was less or no greater than the increases seen between the preceding attempts. Paired testing failed to show a significant improvement in performance in any of the three types of exercise after administration of placebo, but significant increases $(p<0.05)$ were found between attempts 2 and 3 in the cycle and step tests and between attempts 1 and 2 in all three types of exercise. The changes in exercise performance between successive attempts are shown in figure 2: although overall performance improved with repeated testing, the increment between successive attempts was little changed or tended to fall.

\section{CORRELATIONS BETWEEN MEASURED}

VARIABLES

The product-moment correlation coefficients (expressed as $\mathrm{r}^{2}$ ) between and across the spirometric values and exercise performance obtained on the final assessment day are summarised in table 2 . There were significant correlations both between the measurements of FEV 1 and FVC and between performance in the various types of exercise test. The correlations between the FEV, or FVC and the various measures of exercise performance were, however, weaker. With the exception of the correlations between the exercise tests on day 1 (which were very poor), repeated testing did not improve any of the correlations between or across the measurements of exercise performance and spirometric values.

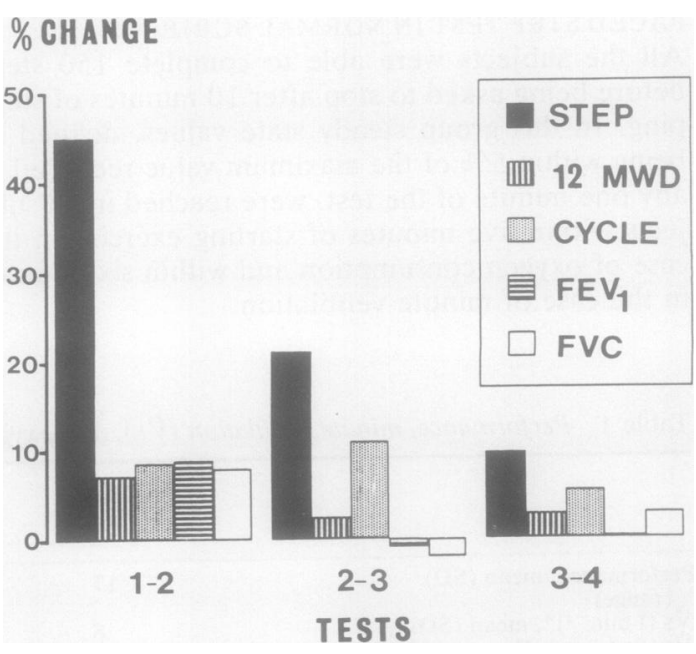

Fig 2 Percentage increase in performance between successive pairs of tests for each of the three types of exercise test. 


\section{Discussion}

The most precise measure of exercise capacity is a formal objective measurement of maximum oxygen uptake ( $\left.\dot{\mathrm{V}}_{2} \max \right)$, the point at which oxygen uptake ceases to increase despite a continuing increase in work rate. Such a test is not possible in many disease states, so symptom limited maxima are used. In this situation maximum exercise performance is determined not only by physiological capacity but also by subjective factors and, perhaps not surprisingly, psychological variables such as attitudes and motivation have been found to be stronger predictors and determinants of the 12 minute walking distance than the FEV, or FVC. ${ }^{34}$ Therein lies the major problem in the application of exercise tests to the assessment of disease and the effect of treatment.

We do not know how closely these patients approached their true physiological maximum exercise capacity in these tests, but the measurements of ventilation and oxygen consumption during exercise may provide some indication. The highest ventilation and oxygen consumption were reached during the step test, in which none of the patients so tested achieved a steady state for ventilation or oxygen consumption, and consequently none sustained the peak levels of ventilation or oxygen consumption that they reached, unlike the normal age and sex matched controls. By contrast, while walking the patients all achieved steady state values for ventilation and oxygen consumption within six minutes, which they were then able to sustain for the remainder of the test. The peak values for ventilation and oxygen consumption while walking were on average $12 \%$ and $15 \%$ respectively, lower than while stepping. This suggests that the patients selected from experience a walking speed just below the maximum level of ventilation and oxygen consumption which they were able to sustain without undue discomfort or fatigue.

An important observation is the continuing improvement in exercise performance clearly seen in all three types of test with repeated testing. This is unlikely to have been due to physical training over such a short period, but it was not surprising in symptom limited tests such as these because increasing familiarity with the tests may have led to an increase in confidence and therefore motivation. The trend for improvement between successive tests became progressively smaller with repeated testing and was no longer significant between the third and fourth attempts, the latter being performed after three days of placebo. We were therefore unable to identify any significant effect of placebo drug on exercise performance that was distinct from the placebo effects of repeated testing. If, however, the placebo had been given after only one or two practice attempts the significant improvements in performance seen in the various types of exercise in this study could have been ascribed to placebo drug effects. The continued trend for improvement in walking distance has been previously noted and emphasised, ${ }^{2}$ but unless recognised improvements in exercise performance after placebo ${ }^{9}$ may be misinterpreted, particularly if only one or two practice attempts are performed.

One reason for questioning the value of exercise tests in the assessment of patients with chronic obstructive lung disease is the poor or absent correlation between 12 minute walking distance and spirometric measurements reported by several authors. ${ }^{1-38}$ Our patients were no different in this respect and in addition we have extended this observation to include the relationship between two other measures of exercise performance and spirometric values. In contrast to the weakness of the exercisespirometry correlations, those between the different types of exercise test were much stronger despite the different end point of each test. In the walking test the end point was average walking speed, in the step test it was endurance at a fixed work rate, and in the cycle test it was a combination of endurance and work rate. This all suggests that the poor exercisespirometry correlations were not simply due to errors in measurement or idiosyncracies in individual forms of test, but rather that exercise tests were, in part, revealing the effects of disturbed lung function that were not wholly evident from changes in spirometric measurements.

What are the merits of these different forms of exercise test? The walking test has the advantage that it is a familiar form of exercise, which may explain in part its good reproducibility and the proportionately small improvements seen on repeated testing. Furthermore, it appears to take the patients reasonably close to their maximum sustainable oxygen consumption. Its principal disadvantage also relates to its familiarity and the self paced nature of the test, which probably account for its observed dependence on attitude and motivation, ${ }^{34}$ its good short term reproducibility, ${ }^{28}$ and the observation that performance in the test is appreciably improved by simple verbal encouragement. ${ }^{6}$ Furthermore, the habitual nature of the chosen walking speed may prevent this test from demonstrating to the full any beneficial effect of treatment. In our patients the range of performance between subjects was relatively small and the reported response to treatment is also often proportionately small. $^{8-11}$

The step test is a measure of the patient's ability to work against gravity, and as such is relevant to 
their mobility beyond the home. This test provided the greatest metabolic and ventilatory stress of the three forms of exercise studied, which probably accounts for the considerably wider range of performance seen between patients and the more consistent correlations seen between performance and spirometric measurements in this test than in the other two. The chief disadvantage of this test was the large improvement seen on repeated testing, although it showed most clearly the tendency for the improvement in performance between successive tests to become smaller (figs 1 and 2).

The cycle test as a measure of exercise capacity had no advantages over the other tests, but it does in general allow more complex and detailed physiological measurements, such as ear oximetry, to be made.

In conclusion, exercise tests provide valid and consistent information concerning the effects of chronic obstructive airways disease on work capacity that cannot be accurately predicted from spirometry. The use of two simple tests, the 12 minute walking test and the paced step test, provides complementary information about the patient's ability to perform exercise. The chief disadvantage of their use is a dependence on motivation and expectation and the trend for improvement seen on repeated testing. This trend for further improvement, and most probably any placebo effects of a drug, may be minimised but not abolished by using at least three or four practice attempts. Until further evidence becomes available we suggest that in short term intervention studies it is necessary to assume that each further attempt beyond the third or fourth may result in a $10 \%$ improvement in steps climbed and a $3 \%$ improvement in the 12 minute walking distance regardless of any therapeutic effect due to pharmacological properties of a drug.

CRS was a Sir Jules Thorn research fellow, and PWJ is a Wellcome senior clinical research fellow.
We thank Miss Annette Skinner for typing the manuscript.

\section{References}

1 McGavin CR, Gupta SP, McHardy GJR. Twelve minute walking test for assessing disability in chronic bronchitis. $\mathrm{Br}$ Med J 1976; i:822-3.

2 Mungall IPF, Hainsworth R. Assessment of respiratory function in patients with chronic obstructive airways disease. Thorax 1979;34:254-8.

3 Morgan AD, Peck DF, Buchanan DR, McHardy GJR. Effect of attitudes and beliefs on exercise tolerance in chronic bronchitis. Br Med J 1983;286:171-3.

4 Sprake CM, Cotes JE, Reed JW. Correlations of 6 minute walking distance and maximal oxygen uptake in chronic lung disease. Clin Sci 1984;66:57P (abstract).

5 Butland RJA, Pang J, Gross ER, Woodcock AA, Geddes DM. Two-, six-, and 12-minute walking tests in respiratory disease. $\mathrm{Br}$ Med J 1982;284:1607-8.

6 Guyatt GH, Pugsley SO, Sullivan MJ, et al. Effect of encouragement on walking test performance. Thorax 1984;39:818-22.

7 Tydeman D, Chandler A, Culot A, Graveling B, Harrison $\mathrm{B}$. How long is exercise training required to produce and maintain maximum improvement in patients with chronic airways obstruction? Thorax 1984;39:226 (abstract).

8 O'Reilly JF, Shaylor JM, Fromings KM, Harrison $\mathrm{BDW}$. The use of the 12-minute walking test in assessing the effect of oral steroid therapy in patients with chronic airways obstruction. $\mathrm{Br} J$ Dis Chest 1982;76:374-82.

9 Mitchell DM, Gildeh P, Rehahn M, Dimond AH, Collins JV. Effects of prednisolone in chronic airflow limitation. Lancet 1984;ii: 193-6.

10 Leitch AG, Hopkin JM, Ellis DA, Merchant S, McHardy GJR. The effect of ipratropium bromide and salbutamol on exercise tolerance in chronic bronchitis. Thorax 1978;33:711-3.

11 Lam WK, So SY, Yu DYC. Response to oral corticosteroids in chronic airflow obstruction. Br J Dis Chest 1983;77: 189-98. 